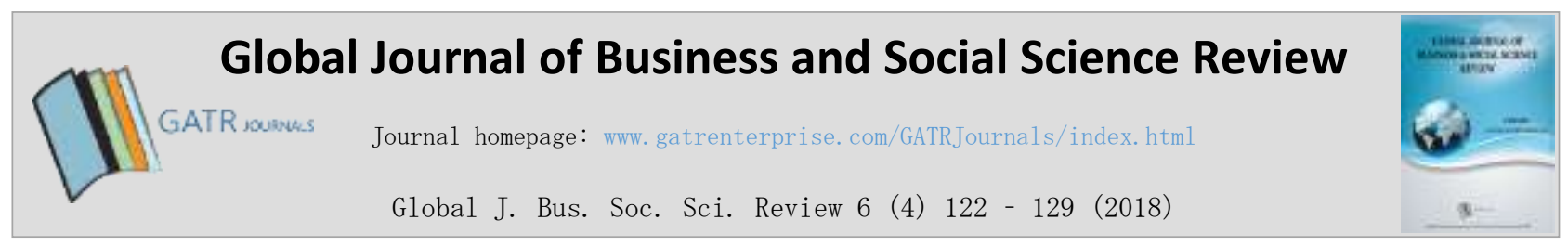

\title{
Managing Non-Governmental Organizations to Create Values in the Disruption Era
}

\author{
Laila Refiana Said
}

Faculty of Business and Economics, Lambung Mangkurat University, Indonesia

\begin{abstract}
Objective - This paper explores the challenges faced by the Indonesia National Council on Social Welfare (INCSW) and its 64 organization members from 31 provinces in Indonesia. INCSW is a social organization that is the coordinating agency for social activities by the Government of Indonesia. The analysis includes strategic management of NGOs in the era of disruption, known as the industrial revolution 4.0.

Methodology/Technique - This study uses a qualitative methodology procedure to produce descriptive data obtained from verbal answers and observable behavior. The data collection methods used in this study include interviews, surveys, observations, and use of documents as secondary data. Open interviews were conducted with several administrators and staff of the Indonesia National Council on Social Welfare (INCSW). Short questionnaires were given to 64 representatives of NGOs from 31 provinces. The interview and survey included questions that probed their understanding of the industrial revolution 4.0, disruptive innovation, willingness to change, and the readiness of the organization to create values in the era of disruption.

Findings - The results show that technology use is still very lacking. The quality of human resources is of minimum concern in digital knowledge. The discussions include observations about the development of management strategies and a variety of programs offered by the Indonesia National Council on Social Welfare (INCSW).

Novelty - This research is one of the few studies that examine non-profit organizations in order to create economic and social values in the era of disruption. This study explains the new paradigm of NGOs by changing the platform of NGO work operationalization. This study widens the application of 'network society' theory in the study of NGOs by emphasizing networks to create value for their stakeholders. The managerial implications of this study include the importance of technology use through social media for social sharing, thus communicating social issues more efficiently and effectively.
\end{abstract}

Type of Paper: Empirical.

Keywords: Change Management; Disruptive Innovation; Human Resources; Industry Revolution 4.0; NonGovernmental Organizations.

JEL Classification: M20, M21, M29.

\section{Introduction}

The disruptive era, which includes significant changes in the use of technology and innovation, has been a

\author{
* Paper Info: Revised: August 15, 2018 \\ Accepted: December 5, 2018 \\ * Corresponding author: Laila Refiana Said \\ E-mail: 1rsaid@ulm.ac.id \\ Affiliation: Faculty of Business and Economics, Lambung Mangkurat University, Indonesia
}


major global topic since 2015. Although it became topic of interest in business and academics in developed countries, the public in Indonesia has only recently begun to open discussions about disruptive innovation, and many are still unaware of this issue. The President of the Republic of Indonesia, Mr. Joko Widodo, responded to disruptive innovation, or the industrial revolution 4.0, in his speech at a meeting with the Indonesian senators on 17 November 2017 (Kuwado, 2017). The President invited every public sector to respond quickly to this change, since disruptive innovation has the potential to bring about massive unemployment due to the many industrial automations. One of the policies adopted by the Government of Indonesia is to accelerate the development of infrastructure to prepare Indonesia to face the new industrial revolution.

Infrastructure development is also expected to facilitate access to public facilities by vulnerable groups, such as people with disabilities. The Government of Indonesia is now tasked with catching up on 30 years of delay in providing access to people with disabilities, compared to other countries that have already done so. Furthermore, due to the existence of the new industrial revolution-where competition in human resources is becoming tighter - there is a need to accelerate infrastructure development in Indonesia.

NGOs, as partners of the government, participate in community services, known as the Social Protection Floor Initiatives (SPF-I). This study examines how NGOs respond to changes brought about by the new revolution industry, how they survive in this era, and the strategies they implement to create more value.

\section{Literature Review}

\subsection{What is Disruptive Innovation?}

Disruptive innovation was initially seen as not beneficial for business people due to the nature of its disruption to existing business routines. The concept of "disruptive innovation" was first coined by Christensen (2017) to illustrate the failure of many firms due to technology disruption. However, over time, a new school of thought around business that opportunities and niche markets can be created as a result of creative thinking to create values for customers. Disruptive innovation can be a positive phenomena as a source of business progress for the organization, however, it can also pose a threat to stakeholders.

Disruptive innovation starts with the process of generating ideas to achieve innovative ideas for customers. To be able to survive in the business world, business people must think creatively and innovatively, and not depend on only one value but offer a variety of values that benefit customers. However, there are various obstacles in disruptive innovation. The following section will discuss disruptive innovation concerning social organizations (NGOs).

\subsection{Creating Values in the Disruption Era}

Various challenges faced by Indonesia, including its readiness to face the disruption era, have had an impact on Indonesian social welfare. A strategy is needed to address industrial transformation, particularly during the "transition period" from traditional old industries to new digital-based industries. The toughest challenge of the industrial revolution 4.0 is the widening of economic inequality (income inequality) between capital owners - both physical and intellectual - with residents who rely on cheap labor. This industrial revolution 4.0 will trigger mass unemployment as almost all work will be replaced by machines (automations).

Disruptive innovation has been widely discussed in terms of its impact on business organizations. However, there is a lack of discussion of the issue in the context of social organizations/non-profit organizations or NGOs (Acker, 2017; Kagermann, 2015). The digital vortex (Figure 1) is an image that depicts how digital disruption redefines various industries. The position of an industry measured from vortex's digital midpoint shows the extent to which an industry will be affected by digital disruption in the next five years. One organization, the Global Center for Digital Business Transformation, created digital 
vortex images based on a survey of 941 business leaders across 12 industries worldwide (International Institute for Management Development, 2016).

Figure 1 shows that the Technology Products and Services industry is the most affected by digital disruption, followed by Media and Entertainment, Retail and Financial Services. This is because these four industries use data more actively than other industries which are more asset-intensive. The sequence continues with Telecommunications, Education, Hospitality and Travel, CPG and Manufacturing, Healthcare, Utilities, Oil and Gas, and Pharmaceuticals.

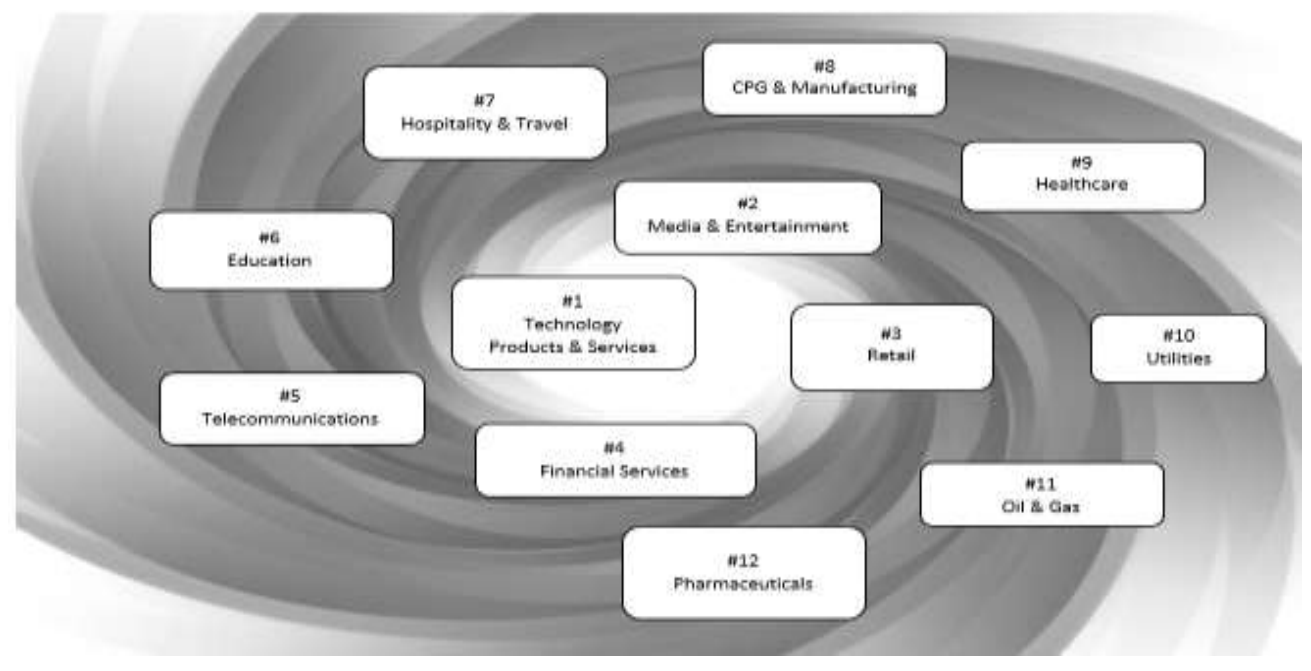

Figure 1. The Digital Vortex

The digital vortex does not address NGOs directly, because those organizations are not viewed as a profit center. However, NGOs must also change their internal paradigm from what was primarily intended as a place for people to contribute to charity. It is necessary for NGOs to hold business units to obtain independent funding sources besides charity. This is known as sociopreneurship when a non-profit organization creates a business unit as its financial engine.

In the era of disruption, NGOs must disrupt their own business to survive and attract more interested partners (individuals and other organizations). This study explores the readiness of non-profit organizations in the era of disruption, focusing on their economic and social value, to improve their operations by minimizing costs and maximizing work efficiency using more digital technology.

\subsection{Network Society}

The present market condition is often referred to as the information age, since almost all people are occupied with various information technologies (Internet Network). Information technology such as the Internet can connect people and modern society in the digital era is now known as the 'network society' (Wikibooks.org, 2013).

According to Castells (1996, 1997b, 2000a), a network society is a social structure that has the main characteristic of an information technology network. Castells $(1996,1997$ a) analyzes the world economy as a new form of economy based on a global and advanced technology era, as well as the existence of social movements. Social movements in one place can quickly spread to other places in the world due to information technology. NGOs will benefit significantly in the digital era if they are able to master technology and utilize networks to disseminate information. 


\section{Methodology}

This study uses a qualitative methodology procedure to produce descriptive data obtained from verbal answers and observable behavior (Taylor \& Bogdan, 2002). As there are still few studies exploring how NGOs face disruptive innovation, a qualitative approach is needed for this research.

The data collection methods used in this study include interviews, surveys, observations, and the use of documents as secondary data. Open interviews were conducted with several administrators and staff of the Indonesia National Council on Social Welfare (INCSW). Short questionnaires were given to 64 representatives of NGOs from 31 provinces. All methods were intended to review and understand the perceptions, attitudes, views, feelings, and behaviors of the informants (respondents).

As the deputy secretary general of Indonesia National Council on Social Welfare (INCSW), the researcher has the opportunity to observe and study the development of this organization, the development and priorities of its programs, as well as organizational management strategies particularly in the disruptive innovation era. Open interviews were conducted between May - July 2018 with the INCSW management and staff focusing on management preparedness in the face of disruption only. The questions probe the management and staff's understanding of the industrial revolution 4.0, disruptive innovation, the willingness to change, and the readiness of the organization in the era of disruption. By studying non-governmental organizations, the study expands on previous research conducted by Pereira and Romero (2017) who focus on the technical concept of industry 4.0 and its technological importance perceived by industrial organizations only.

\section{Result and Discussion}

\subsection{Results}

\subsubsection{Description of the Research Object}

Based on the Charter of Incorporation of the National Committee for Social Welfare, the Indonesian National Council on Social Welfare (INCSW) was established on 17 July 1967, for an unspecified period with a vision of achieving an advanced, prosperous and equitable Indonesian society through empowerment and development programs. The INCSW is an open, independent, non-profit organization that upholds the principle of accountability and social responsibility, equal opportunity and non-discrimination. Pancasila (The Five Principles of the State of the Republic of Indonesia) is the basic principle of the INCSW.

INCSW has a legal status as a national coordinating body of all social organizations in Indonesia and serves as a coordinating and consulting agency to its social organization members. With the publication of Social Welfare Law No. 11 of 2009, and through the Ministry of Social Affairs Decree No: 72 / PLA / 2010, INCSW has been appointed as the Social Welfare Coordinating Board at the national level. With this law, INCSW has an official coordinating role in the maintenance of the social well-being of society. Its duties include coordinating and guiding organizational/social institutions, developing models of social welfare services, conducting communication and consultation forums of social welfare activities, as well as advocating social and financial issues for social organizations.

The INCSW organizational structure comprises the National Assembly, Representative Body, Executive Board, and Advisory Board. The National Assembly holds the highest authority of the organization. It is conducted once every 4 (four) years and attended by all the INCSW members. The Representative Body is selected in the National Assembly and consists of representatives of INCSW's member organizations, individuals and prominent figures based on their capacity, the merit of their service and their dedication to social welfare and social development. The Advisory Board provides written or unwritten, solicited and unsolicited advice to The Executive Board of the INCSW.

The composition of the INCSW Executive Board is varied. The Executive Board of the INCSW between 2009 and 2017 consisted of 22 persons, including 1 Chairman, 1 Vice Chairman, 13 Chairpersons, 1 
Secretary-General, 3 Deputy Secretary-General, 1 Treasurer and 2 Deputy Treasurers. The composition of the members of the INCSW Executive Board between 2017 and 2021 period consists of 20 persons including 1 Chairman, 1 Vice Chairman, 13 Chairpersons, 1 Secretary-General, 2 Deputy Secretary-General, 1 Treasurer and 1 Deputy Treasurer. The INCSW members consist of:

1. Ordinary members include the Social Welfare Coordinating Boards at the provincial level.

2. A number of national social organizations, the organization that engages in social welfare and social development activities where its area coverage is at least within 10 (ten) provinces.

The INCSW partners include:

1. Agencies / Government Agencies concerned in the business of providing social welfare,

2. Government-owned or private organizations, individual and community leaders.

3. Foreign Institutions of Social Welfare.

As an organization based on a global organization, the International Council on Social Welfare (ICSW), which is one of the main objectives of the INCSW, is to fight poverty, inequality and marginalization, as well as to empower vulnerable groups in economic, social and environmental challenges, including, among others, being responsive to natural disasters. Therefore, the focus of the INCSW program is to enhance community empowerment in the socio-economic field through its authority and duties as the partner of the Government of Indonesia, particularly in partnership with the Ministry of Social Affairs.

\subsubsection{Interview Results}

Primary data was obtained from open interviews with INCSW management and staff about management preparedness in the face of disruption and a survey to 64 representatives of INCSW's members. INCSW management and staff were represented by 5 executive board members and 10 staff members. The interview and survey included questions that probed their understanding of the industrial revolution 4.0, disruptive innovation, the willingness to change, and the readiness of the organization in the era of disruption. Among 79 research informants, only 21 people knew about the industrial revolution 4.0 and disruptive innovation. After providing some brief information regarding industrial revolution 4.0 and disruptive innovation to the respondents, all of them were asked whether they would like to see change with respect to increased use of technology. All of the respondents provided positive responses to this, even though not all staff used computers on a daily basis. These results show that technology use is still very lacking.

At present, the management and programs of the INCSW have transformed the use of technology in Indonesia from the previously conventional method to increased use of digital technology, in areas ranging from office facilities and operations to community empowerment programs. Between 2009 and 2017 and 2017 and 2021, the keywords of the INCSW program remain the same, namely the empowerment program. However, the programs conducted between 2009 and 2017 related to aspects of technology use focused primarily on computer training for people with disabilities. The 2017-2021 period is more of an 'eye-opening' or awareness program in dealing with disruptive innovation, one of the programs conducted is foreign exchange (forex) trading training to encourage and improve self-reliance in social organizations.

In many provinces in Indonesia, the training provided is still in its early stages of introducing technology, including computer training for people with disabilities. Based on the interview and survey results, social organizations could focus their efforts on implementing, among other things, virtual offices, data clouds, and online socio marketing. There is an effort to adjust the management strategy and programs offered in addressing the era of disruption. However, those efforts have not yet been implemented. Management acknowledges the difficulty of realizing these idea because many staff only can use computers for office administration purposes and to upload/update reports online. 


\subsection{Discussion}

All research participants showed positive responses regarding the fourth industrial revolution and how they should face it. This result is in consistent with a study conducted by Ślusarczyk (2018) that examined the perceived readiness and responses of people from several types of organizations including non-profit organizations (state organizations). However, the readiness of each organization differs due to variance in their available resources.

Based on the data released by the Association of the Indonesia Internet Service Providers (2017), the number of Internet users in Indonesia rose to 143 million people in 2017 (APJII, 2017). However, Internet use is not a means of increasing productivity for most users in Indonesia. For most Indonesians, the internet is merely a medium of communication and entertainment.

The use of cloud technology and big data analytics for the operationalization of work has not been widely carried out by the NGOs examined in this study. In this way, various data relating to social issues and social welfare is ambiguous. For example, data concerning vulnerable groups will be different between ministries. The use of technology in the era of disruption must be optimized, starting with conducting accurate surveys in the field to update online data regularly so the data can be accessed. The more networks exist, the higher the sharing of benefits obtained by all parties, thus the more significant value for stakeholders.

NGOs in the digital era should not merely offer programs, but must offer an ecosystem or life (platform) of doing business. The main objectives of the Indonesia National Council on Social Welfare (INCSW) is to fight poverty, inequality, and marginalization, as well as empower groups to face economic, social, and environmental challenges, including being responsive to natural disasters. All of these objectives cannot be carried out by the INCSW itself, nor can they be carried out by the Government alone. Connectivity and synergy among many concerned parties is needed to achieve these goals.

Indonesia, as one of the countries prone to natural disasters (UNDP, 2018), needs NGOs that can optimize the network society to anticipate and quickly overcome natural disasters. One of the tasks of the INCSW is social advocacy for the community about the readiness of the community in dealing with disasters, particularly for people with disability. Castells (2000b) argues that the network society has two characteristics namely: 'timeless time' and 'the space of flows' (Castells, 2000b). Information and knowledge on ways to anticipate and mitigate natural disasters can be better acknowledged through NGO websites. Further, the use of technology will enable training sessions to be quickly carried out throughout the province through the use of websites and online training (Castells, 2000b). Therefore, the INCSW website and social media management must be optimized.

\section{Conclusion}

In the era of disruption, NGOs must adapt the way that their organization works to ensure their long term sustainability. This study makes the following suggestions:

Master of technology: Technology needs to be controlled by NGOs in order to speed up the dissemination of information on how to deal with social problems, such as natural disasters, food crises, and others. The industry revolution 4.0 era will reduce employment opportunities as many jobs become automated. For social organizations, the workforce cannot be automated because of the nature of their work that requires strategic decisions. However, what is needed by NGOs in this disruptive innovation era is people who have mastered the technology.

Virtual office: Technology-savvy human resources under the age of 40 years prefer the use of faster communication online. The millennial generation is very mobile. Virtual offices are also needed to reduce unnecessary operational costs. Data stored in the cloud significantly improves the efficiency of organizations, thus creating more value for their stakeholders. 
Organizational restructuring: Non-profit organizations must be realistic in terms of their financial situation. Therefore, a simple organizational structure, such as matrix, is needed.

Empowerment and training programs for the community are needed for the organization to adjust to the current issues of global social policy, particularly for people with disabilities.

Networking is also needed among Organizations, Governmental Organizations (GO) and NGOs, as well as with companies to utilize their CSR programs. NGOs may cooperate with universities and various professional organizations. In the era of the revolution industry 4.0 , networking can be conducted digitally. With this new platform, NGOs can work together with various professions and student apprentices from fields such as psychology and social work online to create more value for the community.

All organizations, including NGOs, must adapt their organization to the era of disruption. The economic and social values of NGOs in this disruptive era depend on the ability of the NGO to effectively network. However, more than 50\% of NGOs studied in this study lack knowledge of the industrial revolution 4.0 and the phenomenon of disruptive innovation. The results show that technology utilization is not yet optimized in these organizations. The new management of the Indonesian National Council on Social Welfare is more responsive and is tasked with adjusting its management structure and programs to address the current issues of global social policy, including the impact and anticipation of the industrial revolution 4.0.

This study uses self-reported data through interviews and surveys to a sample of national nongovernmental organizations (NGOs) in Indonesia as members of the Indonesian National Council on Social Welfare. Future studies should address the research questions to a wider group of NGOs, including international NGOs operating in Indonesia, in order to gain a more comprehensive understanding of their strategic management to create value in the era of disruption.

\section{References}

Acker, R. (2017). Five Ways the Fourth Industrial Revolution Will Transform NGOs. Available at http://www.weforum.org.

Aiken, M. (2016). The Cyber Effect: A Pioneering Cyberpsychologist Explains How Human Behaviour Changes Online. London: Hodder \& Stoughton General Division.

APJII, (2017). Penetration and behavior of Indonesian internet users 2017. Available at https://www.apjii.or.id/content/read/39/342/Hasil-Survei-Penetrasi-and Internet-Indonesia-User-Behavior-2017

Castells, M. 1996. The Rise of the Network Society. New York: Blackwell.

Castells, M. 1997a. An introduction to the information age. City, 7, 6-16.

Castells, M. 1997b. The Power of Identity. Oxford: Blackwell.

Castells, M. 2000a. End of Millennium. Oxford: Blackwell.

Castells, M. (2000). Toward a sociology of the network society. Contemporary sociology, 29(5), 693-699.

Christensen, C.M. 1997. The Innovator's Dilemma: When New Technologies Cause Great Firms to Fail. Boston, MA: Harvard Business School Press.

ICSW 2018. International Council on Social Welfare. Available at http://www.icsw.org/

International Institute for Management Development 2016.Strategies for responding to digital disruption. Available at https://www.imd.org/research/publications/upload/insights-IMD-no-59-Responding-to-Digital-Disruption-DBT-Centerinsights-imd-31-05-16.pdf

Kagermann, H. (2015). Change through digitization-Value creation in the age of Industry 4.0. In Management of permanent change (pp. 23-45). Springer Gabler, Wiesbaden.

Kuwado, F.J. 2017. Jokowi invited the Indonesian people to prepare, the 4th industrial revolution had arrived. Available at https://nasional.kompas.com/read/2017/11/17/17110421/jokowi-ajak-masyarakat-indonesia-iapiap-revolusi-industrike-4-ttiba

Pereira, A. C., \& Romero, F. (2017). A review of the meanings and the implications of the Industry 4.0 concept. Procedia Manufacturing, 13, 1206-1214.

Ślusarczyk B. 2018. Industry 4.0 - are we ready? Polish Journal of Management Studies, 17, 1, 232-248. 
Taylor, S.J. \& Bogdan, R. 2002. Introduction to Qualitative Research Methods. 3rd edition. New York, NY: John Wiley \& Sons, Inc.

Wikibooks.org, 2013. Communication theory.

https://upload.wikimedia.org/wikipedia/commons/5/51/Communication_Theory.pdf

Available

at 